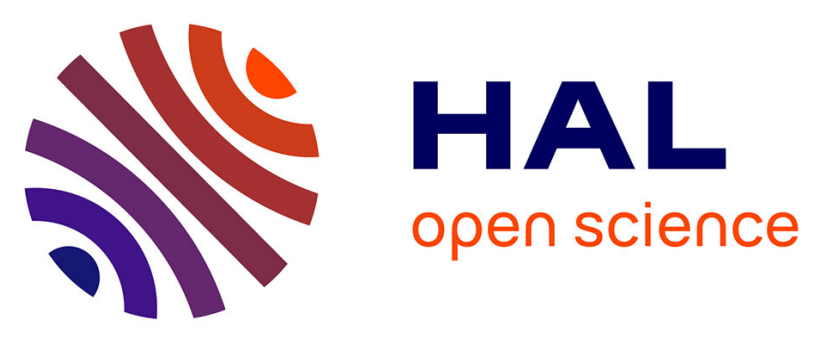

\title{
Rare myopathy associated to MGUS, causing heart failure and responding to chemotherapy
}

Nicolas Belhomme, Adel Maamar, Thomas Le Gallou, Marie-Christine Minot-Myhié, Antoine Larralde, Nicolas Champtiaux, Olivier Benveniste, Sarah Leonard-Louis, Olivier Decaux, Alain Lescoat, et al.

\section{To cite this version:}

Nicolas Belhomme, Adel Maamar, Thomas Le Gallou, Marie-Christine Minot-Myhié, Antoine Larralde, et al.. Rare myopathy associated to MGUS, causing heart failure and responding to chemotherapy. Annals of Hematology, 2017, 96 (4), pp.695-696. 10.1007/s00277-016-2916-3 . hal-01558317

\section{HAL Id: hal-01558317 \\ https://hal-univ-rennes1.archives-ouvertes.fr/hal-01558317}

Submitted on 25 Sep 2017

HAL is a multi-disciplinary open access archive for the deposit and dissemination of scientific research documents, whether they are published or not. The documents may come from teaching and research institutions in France or abroad, or from public or private research centers.
L'archive ouverte pluridisciplinaire HAL, est destinée au dépôt et à la diffusion de documents scientifiques de niveau recherche, publiés ou non, émanant des établissements d'enseignement et de recherche français ou étrangers, des laboratoires publics ou privés. 


\section{Rare myopathy associated to MGUS, causing heart failure and responding to chemotherapy}

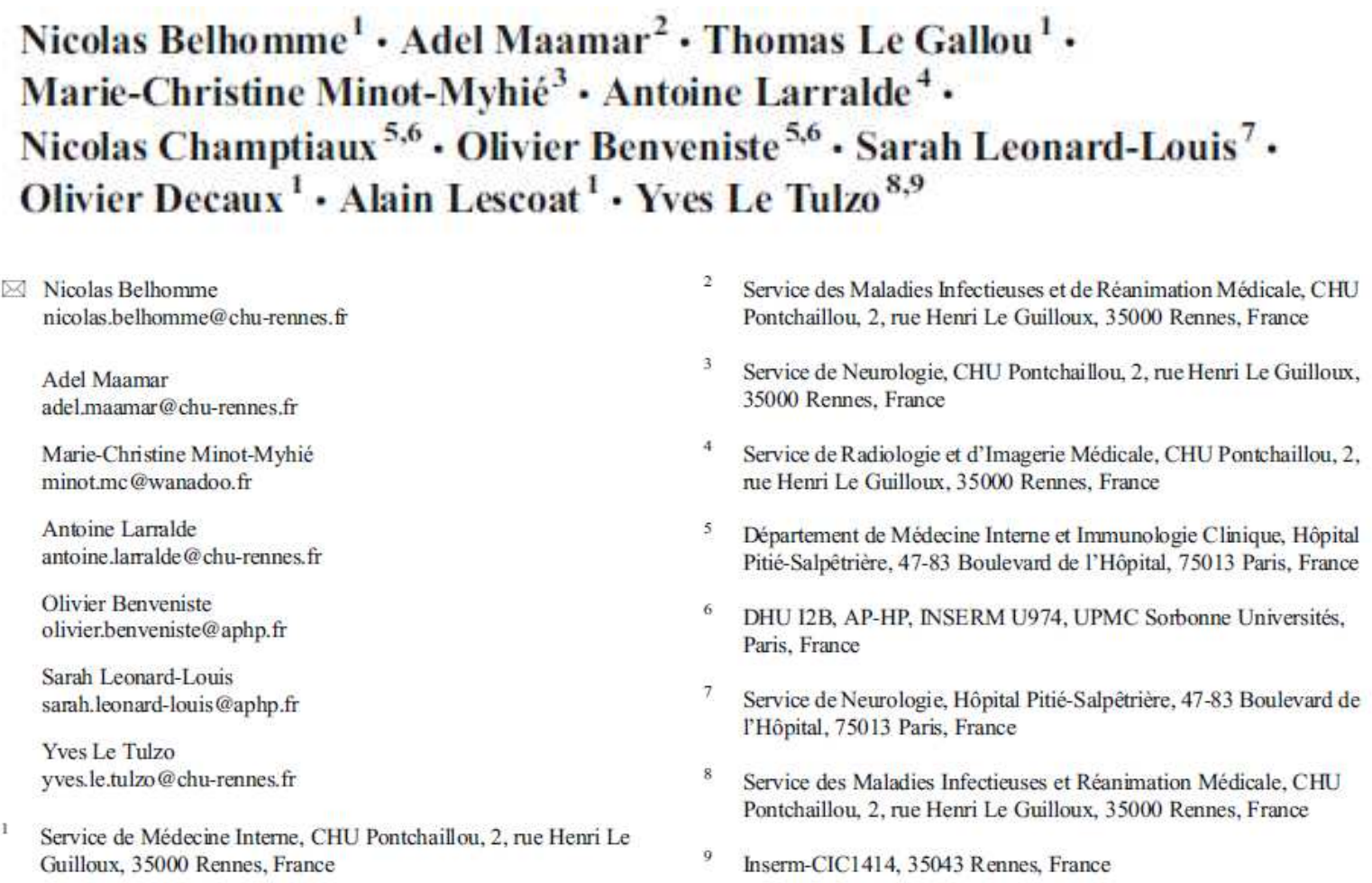

\section{Keywords}

Sporadic late onset nemaline myopathy

Monoclonal gammopathy of unknown significance

Heart failure

Nemaline myopathy related cardiomyopathy

Chemotherapy

Sarcoplasmic rods

Electron microscopy

Dear Editor,

Monoclonal gammopathy of unknow significance (MGUS) has recently been described as a possible cause of sporadic late onset nemaline myopathy (SLONM), which can lead to severe muscle impairment and respiratory insufficiency. We report the case of a man presenting a MGUS related SLONM, whose singularity was a severe heart involvement.

A 55year old man was admitted in the internal medicine department, for severe limb, trunk, and neck muscles weakness, and difficulties to walk. Usual biological tests were normal, and serum electrophoresis revealed a non 
quantifiable IgG $\lambda$ spike, with no multiple myeloma criteria. Muscular MRI showed proximal muscular atrophia, and electromyogram identified myopathic changes in the deltoid muscles. Muscle biopsy, including immunohistochemistry and molecular biology, was normal.

Eighteen months later, dysphagia and severe respiratory muscles impairment developed. Supposing an inflammatory myopathy, 3 cycles of intravenous immunoglobulins (IVIG) were administered, combined with corticosteroids, without clinical improvement.

Another muscular biopsy revealed atrophic basophilic fibers, with no necrosis.

Cryosection examination revealed blackish sarcoplasmic rods (Fig. 1 ), confirmed in electron microscopy. Histological findings, combined with abnormal electrophoresis, led to diagnosing SLONM secondary to MGUS.

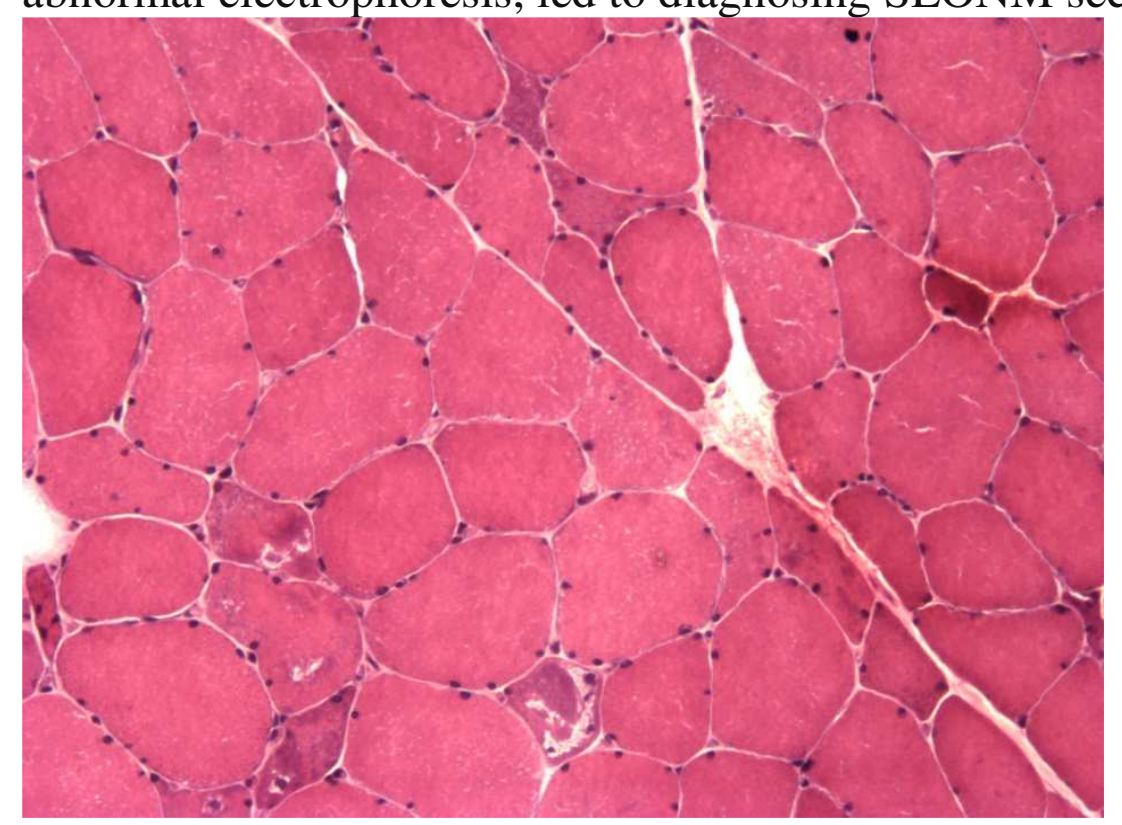

Fig. 1

Deltoïd biopsy with frozen sections. Variation in size fiber with many atrophic and angulated fibers and black sarcoplasmic deposits corresponding to rods

Three months later, the patient was admitted in the intensive care unit with acute heart failure. Troponin levels were slightly increased, and angiography of the coronary arteries was normal. Echocardiography revealed a severe systolic dysfunction with no signs of pulmonary hypertension, and no evidence of stress related cardiomyopathy. Cardiac resonance imaging (MRI) confirmed severe left ventricular dysfunction (LVEF 30\%), without any ventricular dilation, inflammation, fibrosis, or microvascular abnormality. Salivary glands biopsy and

subcutaneous abdominal fat aspiration were normal, ruling out cardiac amyloidosis.

We then suspected that recent cardiac failure was linked to the MGUS related 
myopathy, and a combination of bortezomib-cyclophosphamidedexamethasone

chemotherapy was administered, together with selective betablockers.

After the fourth cycle, we observed a significant improvement in both motricity and cardiac function, with the disappearance of clinical cardiac insufficiency symptoms and an increase in LVEF from 30 to $60 \%$, supporting the hypothesis of an SLONM related cardiomyopathy.

Nemaline myopathy is clinically characterized by a progressive muscular atrophy and a deficit predominating on proximal limb and trunk muscles. The histological hallmark of the disease is the detection of dark sarcoplasmic rods, called nemaline, inside atrophic muscular fibers. In most cases, nemaline myopathy is congenital, but recently, cases were described in adults and considered as "sporadic late onset nemaline myopathy" (SLONM). Associations of SLONM with MGUS were found not to be a coincidence [ 1 ]. In such cases, stem cell transplantation (SCT) demonstrated some efficacy [ 2 ], but such treatment was not considered at first for our patient, given his vulnerability. Cardiac disease in SLONM is not infrequent and can take various forms, as described by Finester et al. [ 3 ]. Early detection of cardiac involvement is essential, since effective treatments can improve patient outcome.

Definitive diagnosis would have required a myocardial biopsy, but as it wouldn't

have influenced the course of treatment, it was deemed unethical. Moreover, a significant cardiac improvement was observed under chemotherapy, which was strong evidence of the link between heart failure and MGUS related SLONM. $F S H D$ facioscapulohumeral muscular dystrophy, ICU intensive care unit, IVIG intravenous immunoglobulin, $L G M D$ limbgirdle muscular dystrophy, $L V E F$ left ventricular ejection fraction, $M G U S$ monoclonal gammopathy of unknown significance, MRI magnetic resonance imaging, SCT stem cell transplantation, SLONM, sporadic late onset nemaline myopathy

\section{References}

1. Doppler K, Knop S, Einsele H, Sommer C, Wessig C (2013) Sporadic late onset nemaline myopathy and immunoglobulin deposition disease. Muscle Nerve 48:983-988

2. Voermans NC, Benveniste O, Minnema MC, Lokhorst H, Lammens M, Meersseman W et al (2014) Sporadic lateonset

nemaline myopathy with

MGUS: longterm

followup

after melphalan and SCT. Neurology 83:2133-

2139

3. Finsterer J, Stöllberger C (2015) Review of cardiac disease in nemaline 
myopathy. Pediatr Neurol 53(6):473-477 